\title{
Optimization of Electrostatic Separation Process for Maximizing Biowaste Recovery Using Taguchi Method and ANOVA
}

\author{
Koonchun Lai ${ }^{1 *}$, Sooking Lim², Pehchiong Teh ${ }^{1}$ \\ ${ }^{1}$ Faculty of Engineering and Green Technology, University Tunku Abdul Rahman, Perak, Malaysia \\ ${ }^{2}$ LKC Faculty of Engineering and Science, University Tunku Abdul Rahman, KL, Malaysia
}

Received: 4 July 2014

Accepted: 23 September 2014

\begin{abstract}
In this study, the electrostatic separation process was employed to recover biowaste from waste mixtures. The recovered biowaste is a potential source of alternative renewable energy (e.g. biomass energy). Taguchi's methodology of experimental design was used for a robust design of both system and random factors. Robust design attempts to analyze the influence of respective factors towards the separation process and, meanwhile, limits the negative impact of the hard-to-control random factors. The effects of four factors, namely voltage level, rotation speed, water content, and particle size diameter were determined. It was noticeable that voltage level has a maximum effect $(39.44 \%)$ on effective recovery of biowaste, followed by size diameter, water content, and rotation speed within design range. On the other hand, the minimal middling product was mostly influenced by the voltage level (79.78\%). The water content has a negligible effect $(0.78 \%)$ if compared to rotation speed and size diameter. This paper concluded the appropriate operational range to have less error from the variations of noise.
\end{abstract}

Keywords: separation, ANOVA, Taguchi method, recovery

\section{Introduction}

Municipal solid waste (MSW) is generally disposed of at landfills, and is highly attributed to its simplest and cheapest disposal procedures if compared to other approaches such as incineration [1]. Landfills bring negative impact to the environment due to leachate and biogas emission for biowaste [2]. A high amount of biowaste, particularly food waste, can be found in municipal waste. Approximately $45 \%$ of municipal solid wastes are organic food waste, followed by inorganic wastes such as plastics and glass [3]. A comprehensive study of food segregation is thus crucial. Segregation of food from waste results in a reduction of organic decomposition arising in a landfill and

*e-mail: laikc@utar.edu.my thus cuts down the generation of leachate. On one hand, the amount of landfill leachate could be lessened with the rare existence of organic matters. On the other hand, the segregated organic substances can be processed independently for methane gas generation, i.e. a green energy for biogas production [4]. Moreover, incineration of these inorganicfree substances produces less residue and toxic gas.

Electrostatic separation provides an effective approach to recovering the reusable matter from solid wastes. It has been widely employed in applications involving the dry separation process, e.g. to recover conductors from non-conducting mixtures [5]. The separation process with a roll-type electrostatic separator sorts the charged bodies from the uncharged under an intensive electric field. It serves as an environmentally friendly way for recycling and reusing the resources without negatively impacting the surroundings [6]. 
Iuga et al. applied the technique in processing granular wastes of chopped electric wires in removing polyvinyl chloride (PVC) wire insulation from copper conductors [7]. Moreover, they utilized the electrostatic force for feldspar extraction from pegmatite, which contains quartz and muscovite mica. They summarized that electrostatic separation is a better way for mineral beneficiation techniques, as compared to flotation method and magnetic sorting, especially for small granular sizes (i.e. $<0.5 \mathrm{~mm}$ ) [8].

Ravishankar and Kolla stated the separation efficiency not only owing to particle sizes, but also other factors, e.g. humidity and temperature [9]. In line with the arguments, several studies have analyzed the different electrostatic separation processes. Elder and Yan concluded that the separation efficiency of mineral sand relies on the rotation speed, electrode configuration, temperature of granule, and other parameters [10]. Besides, Aman et al. identified the supply potential as one of the key factors (in spite of electrode position) for metal recovery [11]. A study from Calin et al. revealed that the different compositions may affect the separation results in separating the plastic mixtures [12]. In brief, the electrostatic separation process is a multi-factorial process that requires the simultaneous control of both mechanical and electrical forces on the granular mixtures [13]. Various parameters affect the performance of the separation process, depending on its experimental design and application.

In order to make the separation process less sensitive to the effects of random variability, this study classifies the various design factors into two groups, namely system factor and random (or noise) factor. Various input parameters of the separator, e.g. voltage level and rotating speed, were defined as system factor due to the possibility of improving system performance significantly. On the other hand, environmental conditions, characteristic variation of samples, and any source of natural occurrences were considered random factors [14]. We propose to having a robust design to reduce the variations of the process conditions caused by the random factor. Robust design refers to a proper experimental arrangement that makes the process insensitive to the sources that are hard to control in practical conditions. This design, implemented using the Taguchi method, is a statistical technique in enhancing manufactured goods quality [15].

The Taguchi method identifies the dominant process parameters and determines the appropriate operational environment in which an experiment is to be performed. It has been applied in a number of industries and proven to be a critical success in controlling the process quality [16]. Basavarajappa et al. [17], Davidson et al. [18], Hsu et al. [19], and Mahapatra et al. [20] utilized Taguchi in analyzing the impacts caused by various parameters. Interactions between empirical factors and responses were discussed. Chiang and Hsieh [21], Comakli et al. [22], Keles [23], and Lin et al. [24] employed the same approach in process optimization and performance evaluation. The aim was to identify the optimal operational conditions. Taguchi experimental design, which is based only on a minimum number of experiments, provides a reliable model for criterion selection and decision making [25].
This paper employs Taguchi to assess the biowaste segregation process from the solid waste mixtures. It is a robust parametric analysis technique with a reduced number of experiments [26]. Biowaste refers to the wasted foods. In the present study, a roll-type electrostatic separator was utilized for biowaste recovery. The schematic of the separator was shown in Fig. 1. The separator delivers the biowaste granules (B) to the right-most tank and the non-biowaste granules (NB) to the left-most. The mixtures of granules that fall to the middle tank are classified as middling product (M) and used as an indicator of recovery efficiency. In the robust design, voltage level and roller rotation speed were defined as system factors [14], whereas the water content and size of biowaste granules were selected as random factors. Water content in biowaste decides its conductivity and likelihood to be moved to the right-most tank. However, this parameter is hard to control in practical conditions [27]. The size of granules, on the other hand, varied due to the machinery limitation. This random factor may eventually lead to low recovery efficiency [28]. Robust design using Taguchi in the present study targets limiting the negative impact of these hard-to-control random factors toward the separation process. To our best knowledge, this is the first robust design report for biowaste separation process using an electrostatic separator.

\section{Experimental Procedures}

Taguchi's methodology of experimental design is based on an orthogonal array arrangement, where the inner array and outer array are, respectively, the system factor and random factor. The four factors, namely voltage level, rotation speed, water content, and particle size diameter were varied by three different levels. In the full factorial design, a total of 34 or 81 sets of experiments are required to be performed and analyzed. However, only nine experiments (L-9 orthogonal array) are required for this four-factor-threelevel system using Taguchi. This has reduced the time and cost to acquire the same necessary information.

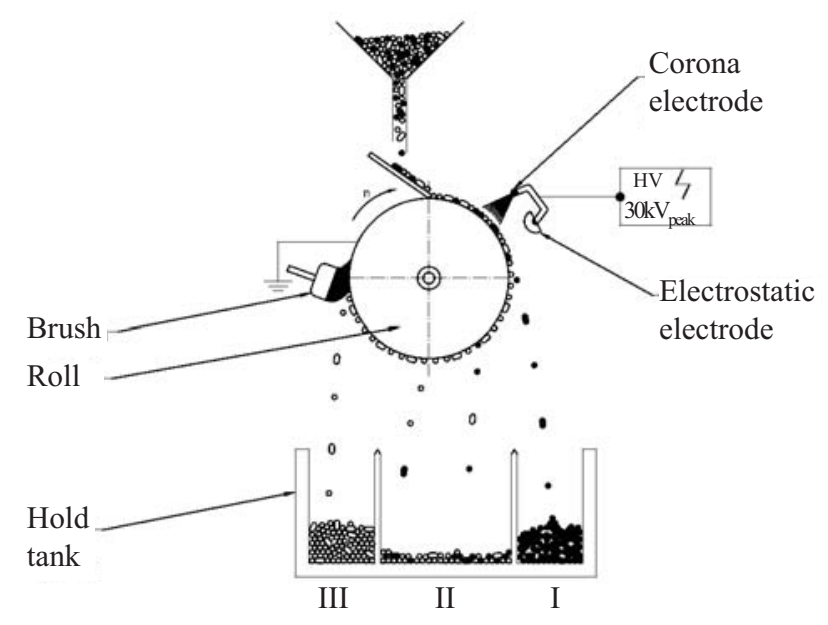

Fig. 1. Electrostatic separation process. 
A signal-to-noise ratio (SNR) is used as the objective function to determine robustness. SNR is viable for replicated experiments to facilitate data filtration and noise reduction. It has been widely employed in stochastic screening and optimization problems as a performance measure [29]. SNR relies on the orthogonal array output, which specifies the effects of various factors on the response formation. There are three different types of objective functions, namely nominal-is-best, larger-is-better, and smaller-is-better. The larger-is-better type of objective function is defined as:

$$
\mathrm{SNR}=-10 \log \left(\frac{1}{n}\right) \sum_{i=1}^{n} \frac{1}{y_{i}^{2}}
$$

...whereas the smaller-is-better type of objective function is calculated by:

$$
\mathrm{SNR}=-10 \log \left(\frac{1}{n}\right) \sum_{i=1}^{n} y_{i}^{2}
$$

...where $n$ is the number of evaluation and $y_{i}$ is the mass collected from holding tanks in each evaluation such that $\left\{y_{i} \mid i=1,2, \ldots, n\right\}$.

Relative influences of the factors on the response can be analyzed by studying the sum of squares $(S S)$ and percentage $(\%)$ effect. The sum of squares can be determined by:

$$
\begin{gathered}
S S=\sum_{i=1}^{N} N(\mathrm{SNR}-\overline{\mathrm{SNR}})^{2} \\
\overline{\mathrm{SNR}}=\frac{1}{N} \sum(\mathrm{SNR})
\end{gathered}
$$

...and percentage effect can be measured by:

$$
\% \text { effect }=\frac{S S}{\operatorname{Dof}\left[\sum(S S / D o f)\right]}
$$

...where $N$ is the number of experiments conducted with the same factor level, SNR is the mean of the SNRs, and Dof is the corresponding degrees of freedom. The percentage effect indicates the significance of the factor on response, i.e. the factor with the highest value of $\%$ effect is more dominant and important than those with lower $\%$ effect.

In order to investigate the impact of the random factors from biowaste, the samples $(1.0-4.0 \mathrm{~mm})$ were prepared synthetically. The water content of biowaste ranged 10$30 \%$. The mass of each sample was $100 \mathrm{~g}$, consisting of 40 wt $\%$ biowaste (fruit skin) and $60 \mathrm{wt} \%$ non-biowaste (plastic, glass). The mass collected from the holding tanks was measured by a precision balance with resolution of $0.1 \mathrm{~g}$ in each run.

Four factors varied within three levels were selected: particle size diameter $(1.0 \mathrm{~mm}, 2.5 \mathrm{~mm}$, and $4.0 \mathrm{~mm})$, moisture or water content $(10 \%, 20 \%$, and $30 \%)$, roller rotation speed ( $60 \mathrm{rpm}, 70 \mathrm{rpm}$, and $80 \mathrm{rpm}$ ), and supplied voltage level $(20 \mathrm{kV}, 25 \mathrm{kV}$, and $30 \mathrm{kV})$. Table 1 tabulates the factors with their corresponding levels.
Table 1. Factors and their levels.

\begin{tabular}{|l|c|c|c|}
\hline \multicolumn{1}{|c|}{ Factor } & Level 1 & Level 2 & Level 3 \\
\hline Particle size diameter, D (mm) & 1 & 2.5 & 4 \\
\hline Biowaste water content, WC (\%) & 10 & 20 & 30 \\
\hline Rotation speed, N (rpm) & 60 & 70 & 80 \\
\hline Voltage level, U (kV) & 20 & 25 & 30 \\
\hline
\end{tabular}

Table 2. Robust design of L-9 orthogonal array.

\begin{tabular}{|c|c|c|c|c|}
\hline $\begin{array}{c}\text { Exp. } \\
\text { No. }\end{array}$ & $\begin{array}{c}\text { Particle size } \\
\text { diameter } \\
(\mathrm{mm})\end{array}$ & $\begin{array}{c}\text { Biowaste } \\
\text { water } \\
\text { content }(\%)\end{array}$ & $\begin{array}{c}\text { Rotation } \\
\text { speed } \\
(\mathrm{rpm})\end{array}$ & $\begin{array}{c}\text { Voltage } \\
\text { level (kV) }\end{array}$ \\
\hline 1 & 1 & 10 & 60 & 20 \\
\hline 2 & 1 & 20 & 70 & 25 \\
\hline 3 & 1 & 30 & 80 & 30 \\
\hline 4 & 2.5 & 10 & 70 & 30 \\
\hline 5 & 2.5 & 20 & 80 & 20 \\
\hline 6 & 2.5 & 30 & 60 & 25 \\
\hline 7 & 4 & 10 & 80 & 25 \\
\hline 8 & 4 & 20 & 60 & 30 \\
\hline 9 & 4 & 30 & 70 & 20 \\
\hline
\end{tabular}

As this is a design of four factors with three levels, an orthogonal array was built and shown in Fig. 2. They were five design points in the inner array, and each of them was surrounded by a square of outer array with other four design points. Thus, nine design points were selected for the Taguchi method to form an L-9 array (Table 2). In general,

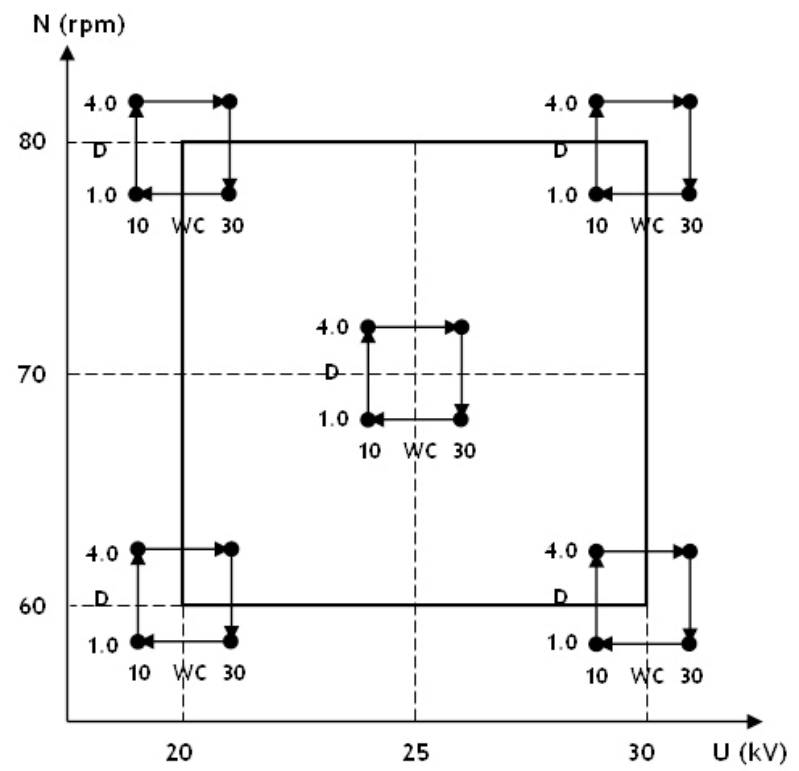

Fig. 2. Inner and outer arrays of the Taguchi method. 
Table 3. Experimental response and the corresponding SNR.

\begin{tabular}{|c|c|c|c|c|c|c|}
\hline Exp. No. & Biowaste, B $(\mathrm{g})$ & $\%$ Recovery & SNR (for B) & Middling, M (g) & \% Recovery & SNR (for M) \\
\hline 1 & 28.9 & 72 & 29.22 & 16.0 & 27 & -24.08 \\
\hline 2 & 32.3 & 81 & 30.18 & 15.1 & 25 & -23.58 \\
\hline 3 & 30.1 & 75 & 29.57 & 14.5 & 24 & -23.23 \\
\hline 4 & 31.4 & 79 & 29.94 & 13.7 & 23 & -22.73 \\
\hline 5 & 30.0 & 75 & 29.54 & 16.8 & 28 & -24.51 \\
\hline 6 & 32.5 & 81 & 30.24 & 14.9 & 25 & -23.46 \\
\hline 7 & 31.5 & 79 & 29.97 & 15.1 & 25 & -23.58 \\
\hline 8 & 34.0 & 85 & 30.63 & 13.4 & 22 & -22.54 \\
\hline 9 & 31.3 & 78 & 29.91 & 15.3 & 26 & -23.69 \\
\hline
\end{tabular}

Table 4. Analysis of different factors on biowaste and middling.

\begin{tabular}{|c|c|c|c|c|c|c|c|}
\hline \multirow{2}{*}{ Factor } & \multirow{2}{*}{ Level } & \multicolumn{3}{|c|}{ Biowaste, B } & \multicolumn{3}{|c|}{ Middling, M } \\
\hline & & SNR & Mean & SS & SNR & Mean & SS \\
\hline \multirow{3}{*}{$\mathrm{D}(\mathrm{mm})$} & 1 & 29.67 & \multirow{3}{*}{29.92} & \multirow{3}{*}{0.13} & -23.64 & \multirow{3}{*}{-23.51} & \multirow{3}{*}{0.07} \\
\hline & 2 & 29.91 & & & -23.60 & & \\
\hline & 3 & 30.18 & & & -23.29 & & \\
\hline \multirow{3}{*}{ WC (\%) } & 1 & 29.71 & \multirow{3}{*}{29.92} & \multirow{3}{*}{0.09} & -23.48 & \multirow{3}{*}{-23.51} & \multirow{3}{*}{0.01} \\
\hline & 2 & 30.13 & & & -23.58 & & \\
\hline & 3 & 29.91 & & & -23.46 & & \\
\hline \multirow{3}{*}{$\mathrm{N}(\mathrm{rpm})$} & 1 & 30.05 & \multirow{3}{*}{29.92} & \multirow{3}{*}{0.08} & -23.39 & \multirow{3}{*}{-23.51} & \multirow{3}{*}{0.12} \\
\hline & 2 & 30.01 & & & -23.35 & & \\
\hline & 3 & 29.69 & & & -23.79 & & \\
\hline \multirow{3}{*}{$\mathrm{U}(\mathrm{kV})$} & 1 & 29.56 & \multirow{3}{*}{29.92} & \multirow{3}{*}{0.19} & -24.10 & \multirow{3}{*}{-23.49} & \multirow{3}{*}{0.79} \\
\hline & 2 & 30.13 & & & -23.54 & & \\
\hline & 3 & 30.06 & & & -22.84 & & \\
\hline
\end{tabular}

the system factors (rotation speed, voltage level) have an effect on the average output of the process, whereas the random factors (size diameter, water content) may or may not influence the values around the average. Outcomes of this study enable dominant factor selection for biowaste recovery from waste mixtures.

\section{Results and Discussion}

The recovered biowaste mass and middling products mass collected from the tanks were used as the experiment responses of the L-9 array. The responses were tabulated in Table 3 with their corresponding SNRs calculated using equations $(1,2)$. This study was to decide the effective separation conditions for maximal biowaste recovery and, meanwhile, minimal middling products. Thus, the larger-is- better and smaller-is-better types of objective functions were applied, respectively. The former type is generally aligned with a positive sign, whereas the latter has a negative SNR value.

Table 4 shows the analysis of SNRs. The sum of square of each factor was calculated using equation (3), whereas the effect of each factor on biowaste recovery and middling was measured by equation (5), as illustrated by Fig. 3. It is noticeable that the voltage level has the maximum effect (39.44\%) on effective recovery of biowaste, followed by the size diameter $(26.93 \%)$, water content $(17.90 \%)$ and rotation speed (15.73\%) within design range. On the other hand, the minimal middling product was mostly influenced by voltage level $(79.78 \%)$. The water content has a negligible effect $(0.78 \%)$ if compared to rotation speed $(12.07 \%)$ and size diameter $(7.37 \%)$. 


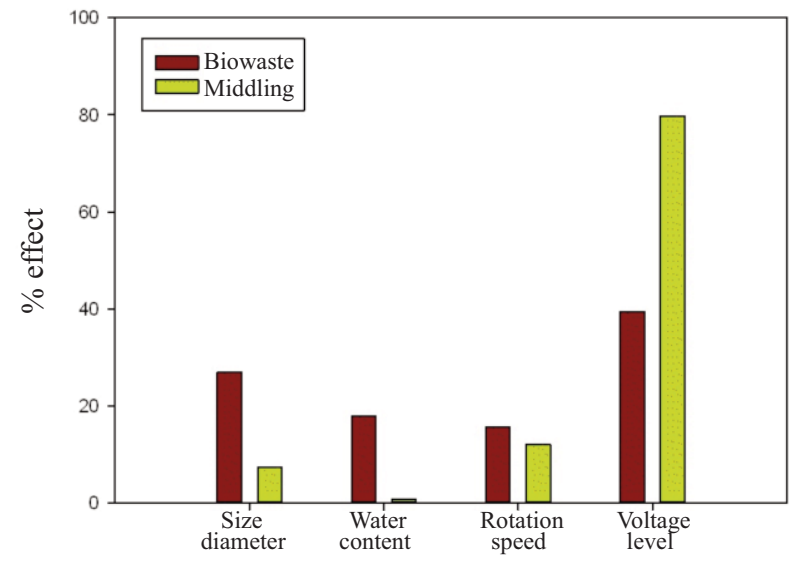

Fig. 3. Factors and their significant effects on the response.

It was unsurprising from Fig. 3 that the voltage level appears as a key factor for electrostatic separation. A high level of supplied voltage implies a large number of biowaste granules that can be attracted toward the biowaste collection tank (tank I). Meanwhile, the non-biowaste granules were effectively pinned and moved to the non-

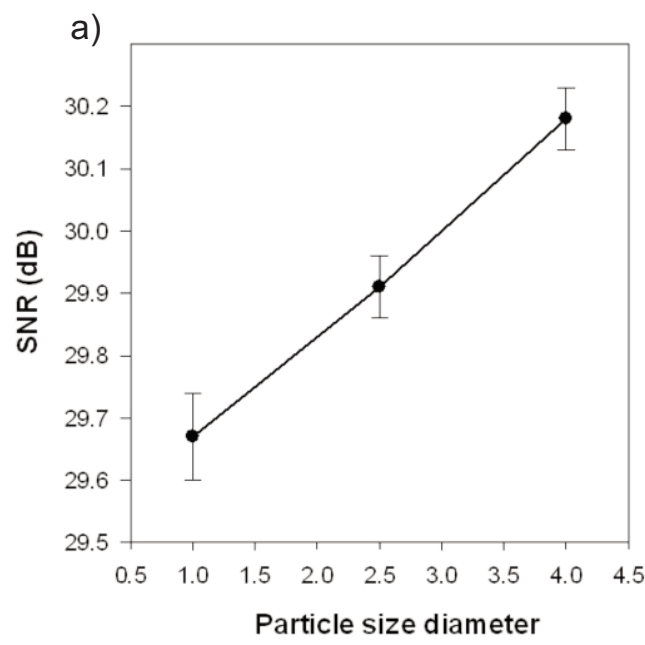

c)

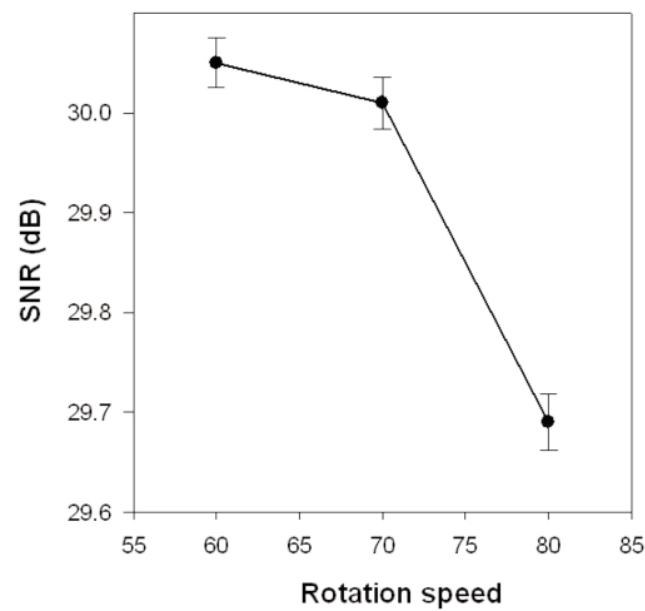

biowaste tank (tank III). Therefore, the middling product dropped within was consequently minimized. A similar phenomenon was observed on particles with large diameters $(4.0 \mathrm{~mm})$. These particles with large surface area were subjected to more attraction and pinning effects, thus making them drop to the collection tanks effectively.

Besides, it is worth noting that the factor water content only applied to biowaste granules, as it improves their conductivity. The factor hence has much greater impact on biowaste recovery results than the middling. This phenomenon is in good agreement with our experimental findings as shown in Fig. 3. The rotation speed of the separator also demonstrated perceptible influences on both responses. This can be explained by the centrifugal force caused by roll speed. Centrifugal force plays a certain role to detach the wastes at the right point, in addition to the attraction and pinning forces induced by the electrodes.

The graphical representation of the effect of design factors on maximal biowaste recovery was shown in Fig. 4. It was apparent that the best situation happened with large particle sizes $(4.0 \mathrm{~mm})$ with $20 \%$ water content under a 60 rpm rotation speed and $25 \mathrm{kV}$ of voltage level. By analyzing the graphical representation of the effect of design fac-

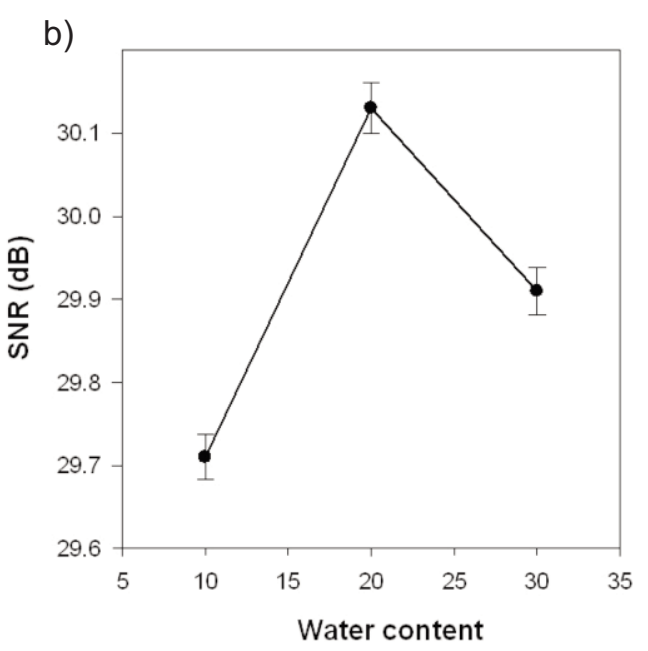

d)

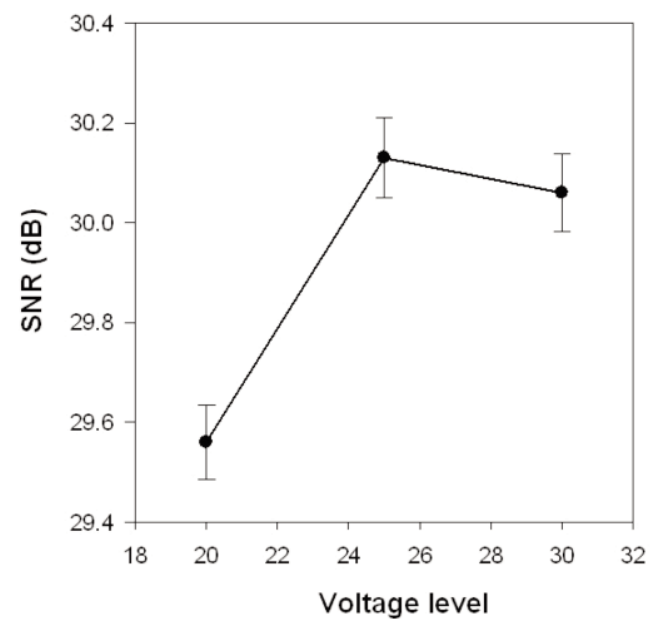

Fig. 4. Effect of factors on SNR for maximal biowaste recovery. 
a)

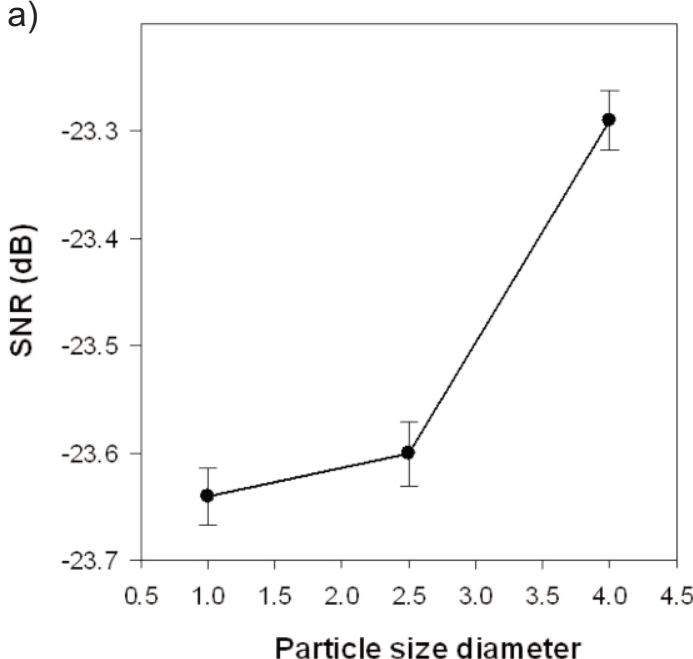

c)

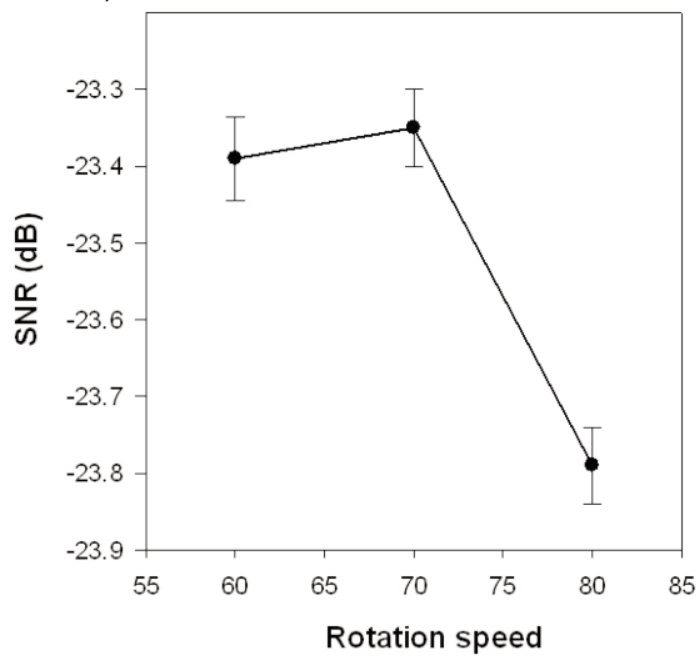

Fig. 5. Effect of factors on SNR for minimal middling product.

tors on the minimal middling product shown in Fig. 5, it was observed that large particle size is preferable. However, water content of $20 \%$ is not good for middling minimization, though it contributes to the maximal recovery of biowaste. Considering the water content does not have much influence on the middling product, $20 \%$ water content of biowaste is an optimum selection.

By studying and comparing Figs. 4 and 5, voltage levels of $25 \mathrm{kV}$ and $30 \mathrm{kV}$ give, respectively, the best maximal biowaste recovery and minimal middling product. Meanwhile, rotation speed of 60-70 rpm has almost on equivalent effect on both SNRs. Therefore, a robust design of biowaste separation process can be achieved at a voltage level of $25-30 \mathrm{kV}$ with a roller rotating within $60-70 \mathrm{rpm}$. With this operational condition arrived at by using the Taguchi method, variations from random factors (i.e. granular particle size and biowaste water content) can be minimized and thus enhance separation efficiency.

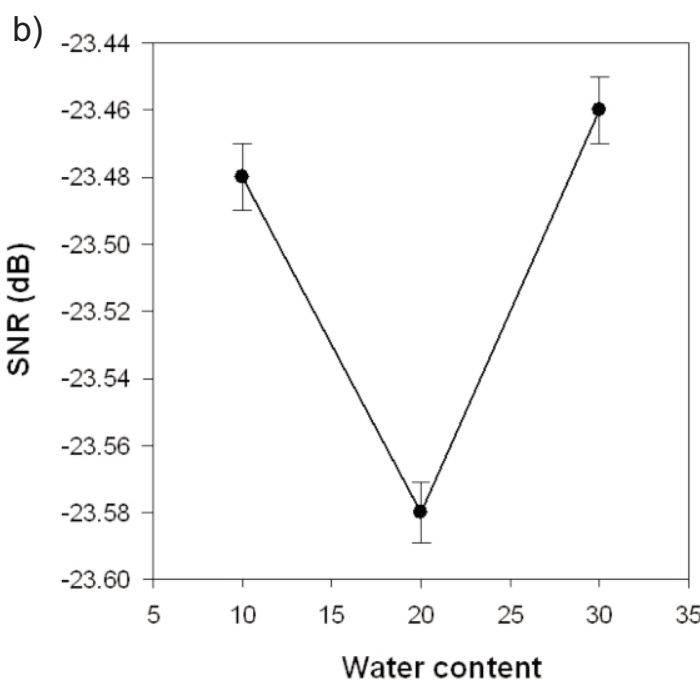

d)

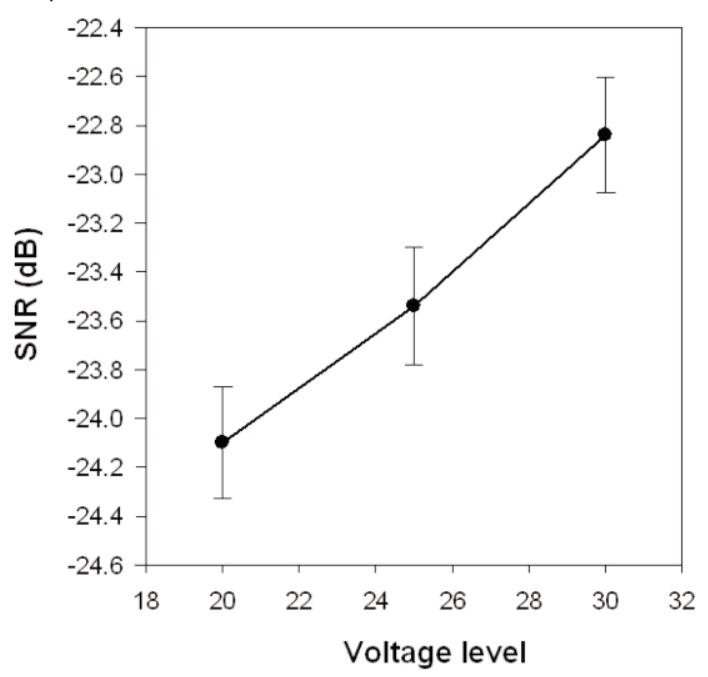

\section{Conclusion}

The Taguchi method provides an approach to improving the performance of processes. The robust design using Taguchi limits the variations of random (noise) factors. It identifies the significant influence of each design factor and determines the type of objective functions. In the present study, the larger-is-better type of objective function was applied for maximal biowaste recovery, whereas the smaller-is-better type of objective function was used to yield minimal middling product. Analysis revealed that the above-mentioned functions can be attained when voltage level is $25-30 \mathrm{kV}$ with rotating speed at $60-70 \mathrm{rpm}$. The study also suggests that the $4.0 \mathrm{~mm}$ particle size of biowaste with $20 \%$ water content causes less error but enhances separation performance. 


\section{References}

1. MAGDALENA V., DANA A. Can vegetation indicate a municipal solid waste landfill's impact on the environment? Pol. J. Envion. Stud. 23, (2), 501, 2014.

2. JAFFRIN A., BENTOUNES N., JOAN A.M., MAKHLOUF S. Landfill biogas for heating greenhouses and providing carbon dioxide supplement for plant growth, Biosyst. Eng. 86, 113, 2003.

3. MOHABUTH N., MILES N. The recovery of recyclable materials from waste electrical and electronic equipment (WEEE) by using vertical vibration separation. Resour. Conserv. Recy. 45, 60, 2005.

4. HOLM-NIELSEN J.B., AL SEADI T., OLESKOWICZPOPIEL P. The future of anaerobic digestion and biogas utilization. Bioresource Technol. 100, 5478, 2009.

5. LAWVERAND J.E., DYRENFORTH W.P. Electrostatic separation in electrostatics and its Applications. A.D. Moore. Ed. New York: Wiley, 221-249, 1973.

6. KIEWIET C., BERGOUGNOU M.A., BROWN J.D. Electrostatic separation of fine particle in vibrates fluidized beds. IEEE T. Ind. Appl., 6, 526, 1978.

7. IUGA A., MORAR R., SAMUILA A., DASCALESCU L. Electrostatic separation of metals and plastics from granular industrial wastes. IEE Proc. Sci. Meas. Tech. 148, 47, 2001.

8. IUGA A., CUGLESAN I., SAMUILA A., BLAJAN M., VADAN D., DASCALESCU L. Electrostatic separation of muscovite mica from feldspathic pegmatics. IEEE T. Ind. Appl. 40, (2), 422, 2004.

9. RAVISHANKAR S.A., KOLLA H. Chemical enhanced electrostatic separation. The $7^{\text {th }}$ International Heavy Mineral Conference 'What next', Heavy minerals, South Africa, 2009.

10. ELDER J., YAN E. eForce...Newest generation of electrostatic separator for the mineral sands industry. Heavy minerals, South Africa, 2003.

11. AMAN F., MORAR R., KOHNLECHNER R., SAMUILA A., DASCALESCU L. High-voltage electrode position: a key factor of electrostatic separation efficiency. IEEE T. Ind. Appl. 40, (3), 905, 2004.

12. CALIN L., NEAMTU V., MORAR R., IUGA A., SAMUILA A., DASCALESCU L. Tribocharging of granular plastic mixtures in view of electrostatic separation. IEEE T. Ind. Appl. 44, (4), 1045, 2008

13. SAMUILA A., URS A., IUGA A., MORAR R., AMAN F., DASCALESCU L. Optimization of corona electrode position in roll-type electrostatic separators. IEEE T. Ind. Appl. 41, (2), 527, 2005.

14. DASCALESCU L., SAMUILA A., MiHALCIOIU A., BENTE S., TILMATINE A. Robust design of electrostatic separation process. IEEE T. Ind. Appl. 41, (3), 715, 2005.

15. TAGUCHI G. Introduction to quality engineering: designing quality into products and processes. Asian Productivity Organization, 1986.
16. DASCALESCU L. Robust corona-electrostatic separation method for solid waste recycling. Int. J. Environ. Waste Manage. 2, 423, 2008.

17. BASAVARAJAPPA S., CHANDRAMOHAN G., DAVIM J.P. Some studies on drilling of hybrid metal matrix composites based on Taguchi techniques. J. Mater. Process. Technol. 1, (3), 332, 2008.

18. DAVIDSON M.J., BALASUBRAMANIAN K., TAGORE G.R.N. Experimental investigation on flow-forming of AA6061 alloys a Taguchi approach. J. Mater. Process. Technol. 1, (3), 283, 2008.

19. HSU W.H., CHAO C.K., HSU H.C., LIN J., HSU C.C. Parametric study on the interface pullout strength of the vertebral body replacement cage using FEM-based Taguchi method. Med. Eng. Phys. 31, (3), 287, 2009.

20. MAHAPATRA S.S., PATNAIK A., SATAPATHY A. Taguchi method applied to parametric appraisal of erosion behaviour of GF-reinforced polyester composites. Wear 1, (2), 214, 2008.

21. CHIANG M.Y., HSIEH H.H. The use of the Taguchi method with grey relational analysis to optimize the thin-film sputtering process with multiple quality characteristic in color filter manufacturing. Comput. Ind. Eng. 2, 648, 2009.

22. COMAKLI K, SIMSEK F., COMAKLI O., SAHIN B. Determination of optimum working conditions R22 and R404A refrigerant mixtures in heat-pumps using Taguchi method. Applied Energy 86, (11), 2451, 2009.

23. KELES O. An optimization study on the cementation of silver with copper in nitrate solutions by Taguchi design. Hydrometallurgy 95, 333, 2009.

24. LIN Y.C., CHEN Y.F., WANG D.A., LEE H.S. Optimization of machining parameters in magnetic force assisted EDM based on Taguchi method. J. Mater. Process. Technol. 7, 3374, 2009.

25. CHOU C.S., HO C.Y., HUANG C.I. The optimum conditions for combination of magnetic particles driven by a rotating magnetic field using the Taguchi method. Adv. Powder Technol. 20, (1), 55, 2009.

26. SENTHILKUMAR K., SENTHIKUMAAR J.S., SRINIVASAN A. Reducing surface roughness by optimising the turning parameters. S. Afr. J. Ind. Eng. 24, (2), 78, 2013.

27. HOU S., WU J., QIN Y., XU Z. Electrostatic separation for recycling waste printed circuit board: a study on external factor and a robust design for optimization. Environ. Sci. Technol. 44, 5177, 2010.

28. WU J., LI J., XU Z. Electrostatic separation for multi-size granule of crushed printed circuit board waste using two-roll separator. J. Hazard. Mater. 159, 230, 2008.

29. BESSERIS G.J. Multi-response non-parametric profiling using Taguchi's qualimetric engineering and neurocomputing methods: Screening a foaming process in a solar collector assembly. Appl. Soft Comp. 22, 222, 2014. 
